\title{
Distinct Antennal Lobe Phenotypes in the Leaf-Cutting Ant (Atta vollenweideri)
}

\author{
L.S. Kuebler, ${ }^{1,2}$ C. Kelber, ${ }^{1}$ and C.J. Kleineidam ${ }^{1 *}$ \\ ${ }^{1}$ Department of Behavioral Physiology and Sociobiology, Biozentrum, University of Wuerzburg, 97074 Wuerzburg, Germany \\ ${ }^{2}$ Evolutionary Neuroethology, Max-Planck-Institut for Chemical Ecology, 07745 Jena, Germany
}

\begin{abstract}
Leaf-cutting ants (Atta vollenweideri) express a remarkable size polymorphism across the two sexual castes (queens and males) but in particular within the worker caste. Worker size is related to behavior (alloethism), separating workers into behavioral subcastes. The neuronal mechanisms underlying differences in behavior within the worker caste are still unknown. In this study, we first compared selected neuropils, in particular, the antennal lobes $(A L)$ in males, queens, and workers. The males' ALs contain three extremely large, sex-specific glomeruli (macroglomeruli; MGs) and in total comprise fewer glomeruli (242) than the ALs of queens (about 346 glomeruli). In contrast to males, the queen ALs contain only one large glomerulus at a lateral position. The largest number of glomeruli was found in workers (396-442). In a previous paper, we described an $M G$ in the workers' $A L$, and, in the second part of this
\end{abstract}

study, we show that within workers two distinct, sizerelated AL phenotypes exist: the MG phenotype (containing a macroglomerulus) and the RG phenotype, with all glomeruli of regular size. This neuroanatomical polyphenism is established during pupal development and separates the worker caste into two neuroanatomical subcastes. Third, we investigate the functional significance of the MG in workers. By using calcium imaging to monitor activity of $A L$ projection neurons, we show that the releaser component of the trail pheromone is represented in the same region as the MG. We propose that phenotypic trait variation in the organization of the ALs leads to differences in odor information processing that finally result in size-related differences in trail-following behavior. J. Comp. Neurol. 518:352-365, 2010.

INDEXING TERMS: polyphenism; insect olfaction; trail pheromones; sexual dimorphism; social organization; odor receptors

Social insects (ants, bees, wasps, and termites) dominate many terrestrial ecosystems, and their tremendous ecological success is based predominantly on division of labor among colony members (Hölldobler and Wilson, 1990; Wilson, 1971). Individual experience and behavioral plasticity of workers lead to distinct task allocation, resulting in an adaptive and flexible colony response (Beshers and Fewell, 2001). More fundamentally, division of labor is based on different developmental patterns separating sexual castes and a worker caste. In general, there are three different castes in social insects, queens, males, and workers, that can be distinguished by several morphological traits. In species with a derived social organization, even within the worker caste, individuals are often highly polymorphic, and size polymorphism is the most conspicuous trait variation (e.g., leaf-cutting ants). Worker polymorphism results mainly from environmental conditions during development and is influenced only to a small extent by genetic differences between workers (Camargo et al., 2007; Hughes and Boomsma, 2007; West-Eberhard, 2005). Thus, in species with polymorphic workers, the individual's development determines its behavioral repertoire, and morphological trait variation restricts or allows an individual to perform certain tasks and thereby enforces division of labor. The morphology may set limits on the behavioral repertoire; however, the basis for behavioral plasticity is the underlying neuronal plasticity. Indeed, neuronal plasticity related to morphological traits has been described in ants with polymorphic workers (Gronen-

Grant sponsor: Deutsche Forschungsgesellschaft; Grant number: SFB $554 /$ A6.

*CORRESPONDENCE TO: Christoph J. Kleineidam, Department of Behavioural Physiology and Sociobiology, Biozentrum, University of Wuerzburg, 97074 Wuerzburg, Germany.

E-mail: kleineidam@biozentrum.uni-wuerzburg.de 
berg, 2008; Gronenberg and Liebig, 1999; Kleineidam et al., 2005).

Leaf-cutting ant workers (genus Atta) exhibit one of the greatest size polymorphisms (a 200-fold variation in body mass) known in ants (Weber, 1972; Wilson, 1980a). Worker size is related to the behavior of workers and their task allocation (alloethism; Wilson, 1980b). The alloethism found in leaf-cutting ants together with morphological traits has led to the classification of distinct but overlapping groups of worker, termed minor workers, major workers, and soldiers (Wilson, 1980b). These are commonly used descriptions of workers performing different tasks in the colony: The smallest workers (minors) mostly stay inside the nest, tending the brood and taking care of the symbiotic fungus that grows on collected leaf fragments. Foraging is performed by workers of intermediate sizes (majors). They cut leaves and transport the fragments on well-maintained foraging trails back to the nest. The largest individuals (soldiers) are responsible for the colony defense (Weber, 1972; Wilson, 1980a). The classification of minors, majors, and soldiers is often challenged by the fact that both body size and morphological traits vary continuously across the workers' size distribution (Lofgren and Vander Meer, 1986).

For ants, the sense of smell is the most prominent sensory modality (Hölldobler and Wilson, 1990). Ants have a well-developed olfactory system, and pheromone communication is essential for regulating social life within their colonies. Recent studies have shown that small and large workers perceive the trail pheromone differently (Kleineidam et al., 2007). Mechanisms leading to such behavioral differences are still unknown, and differences in how sensory information is processed are assumed to play a prominent role. Indeed, small and large workers are known to differ in the neuroanatomy of the first olfactory neuropil, the antennal lobe (AL; Kleineidam et al., 2005).

In comparison with most other insects, the ALs of ants contain a high number of olfactory glomeruli (Goll, 1967; Kelber et al., 2009; Nishikawa et al., 2008; Schachtner et al., 2005; Zube and Rössler, 2008). Glomeruli are densely packed spherical structures constituting the functional units of the AL. Olfactory receptor neurons (ORNs) carry the odor information via the antennal nerve (AN) to the $A L$, where they synapse with two other neuron classes: projection neurons (PNs) and local neurons (LNs). The PNs relay to higher brain centers such as the mushroom body and the lateral protocerebrum, whereas $\mathrm{LNs}$ are restricted to the $\mathrm{AL}$, where they interconnect between glomeruli and provide information processing within glomeruli (for reviews see de Bruyne and Baker, 2008; Hansson and Anton, 2000; Hildebrand and Shepherd, 1997; Homberg et al., 1989; Mustaparta, 1990). Each olfactory sensory neuron expresses a single and specific olfactory receptor (OR) gene (Clyne et al., 1999; Dobritsa et al., 2003; Hallem et al., 2004). Studies on, e.g., Drosophila melanogaster have shown that ORNs expressing the same OR gene converge into individual glomeruli of the AL (Couto et al., 2005; Fishilevich and Vosshall, 2005). As a consequence of this ORN sorting, odors are represented as spatial patterns of neuronal activity in the AL (Galizia et al., 1999; Joerges et al., 1997).

For several insect species, disproportionately large glomeruli with sex-specific function have been described in males of, e.g., moths (Anton and Homberg, 1999) and also honeybee drones (Arnold et al., 1985; Sandoz, 2006). For sexuals of leaf-cutting ants, the neuroanatomy of the $A L$ has not been investigated so far, and little is known about the sex pheromone system. In this study, we compare the organization of the ALs across the three castes of leafcutting ants and relate the size of the AL to other selected neuropils.

We found in a previous study that the ALs of large leafcutting ant workers contain one substantially larger glomerulus (macroglomerulus; MG) located at the root of the AN (Kleineidam et al., 2005). Small workers supposedly have a corresponding glomerulus (target of the same ORN type) at a similar position in the AL. The formation of an MG in large workers is a result of an disproportionately large number of terminating ORNs, and, based on sensory physiology (electroantennography), it is suggested that one important component of the trail pheromone is represented in the MG (Kleineidam et al., 2005). Whether the size of this glomerulus varies continuously across workers of different sizes was unknown, and this question is addressed here.

The current study investigated phenotypic brain plasticity within the antennal lobes of the leaf-cutting ant Atta vollenweideri. In particular, we sought to reveal the neuronal basis for distinct behavioral repertoires by analyzing quantity (number) and volumes of glomeruli 1) across the three castes (queens, males, and workers) and 2) across workers of different sizes.

\section{MATERIALS AND METHODS \\ Ants}

A colony of Atta vollenweideri (Forel) was reared the Biozentrum, University of Wuerzburg, in an environmental chamber at $25^{\circ} \mathrm{C}$ and $50 \%$ relative humidity on a 12 -hour/ 12-hour photoperiod. It was collected as a small founding colony with some workers in 2002 in El Bagual, Formosa, Argentina (by F. Roces and M. Bollazzi). Six plastic boxes $(19 \times 19 \times 19 \mathrm{~cm})$ interconnected with plastic tubes provided an artificial nest, and the colony was supplied with fresh leaf material (various species of Rosaceae) as substrate for the fungus in one of the six plastic boxes, or 
the workers were allowed to forage across a wooden bridge $(\sim 1 \mathrm{~m})$ to an additional feeding box. Workers were collected from the feeding box or were directly taken from the boxes containing the fungus garden (small workers).

According to the coloration of the cuticle, none of the adult workers was newly hatched. Pupae at late developmental stages (as indicated by their dark eyes) were taken directly from the fungus garden.

Queens (virgin queens) and males were collected (by F. Roces) in 2004 and 2006 at the same field site as the founding colony. The head capsule was opened with a razor blade to allow fast penetration of the fixative ( $4 \%$ formaldehyde) in which the specimens were stored and transported to Germany. The variation in body size of queens and males was assessed from sexuals collected at the Parque Nacional Río Pilcomayo (Formosa, Argentina) in 2008 (by C.J. Kleineidam).

\section{Neuroanatomical procedures and volume measurements}

Workers were first anesthetized with $\mathrm{CO}_{2}$, and both workers and sexuals were decapitated. Heads were mounted in wax dishes, which were then filled with ice-cold saline solution (127 mM NaCl, $7 \mathrm{mM} \mathrm{KCl,1.5} \mathrm{mM} \mathrm{CaCl}$, $0.8 \mathrm{mM} \mathrm{Na}_{2} \mathrm{HPO}_{4}, 0.4 \mathrm{mM} \mathrm{KH}_{2} \mathrm{PO}_{4}, 4.8 \mathrm{mM}$ TES, $3.2 \mathrm{mM}$ trehalose, $\mathrm{pH}$ 7.0). Head width (HW, distance between the outer rims of the eyes) was measured with a digital micrometer caliper (Digimatic Series 350; Mitutoyo, Japan). Subsequently, the brains were dissected from the head capsule and immediately transferred to ice-cold 4\% formaldehyde in phosphate-buffered saline (PBS; pH 7.2) for at least 2 hours. Subsequently, brains were transferred to a second ice-cold fixation solution (FixMix: 2\% formaldehyde and $2 \%$ glutaraldehyde) and stored for 3-4 days at $4^{\circ} \mathrm{C}$. The second fixation procedure considerably facilitated the $3 \mathrm{D}$ reconstruction by an increase of background fluorescence at the wavelength $(561 \mathrm{~nm})$ used for confocal microscopy. The outlines of glomeruli were then much easier to detect. After fixation, brains were dehydrated in an ascending series of ethanol (50\%, 70\%, 80\%, 90\%, 95\%, and $3 \times 100 \%, 10$ minutes each), transferred to methylsalicylate (M-2047; Sigma-Aldrich, Steinheim, Germany), and finally positioned in custom aluminium slides (500-800 $\mu \mathrm{m}$, depending on brain size), which were then sealed with a coverslip. The whole-mount preparations were examined with a laser scanning confocal microscope (Leica TCS SP2; Leica Microsystems, Wetzlar, Germany) equipped with an argon/krypton laser and a $\times 20,0.7-N A$ objective lens $(\mathrm{HC}$ PL APO IMM; Leica Microsystems). Optical sections $(1,024 \times 1,024$ pixel) were taken at intervals of $1 \mu \mathrm{m}$ for reconstruction of the $\mathrm{AL}$ and glomeruli or 2-4 $\mu \mathrm{m}$ for reconstruction of the whole brain and neuropils, using appropriate pinhole settings. 3D reconstructions and volumetric measures were carried out in Amira 3.1 (Mercury Computer Systems, Berlin, Germany). Neuropils were reconstructed by segmentation, followed by either interpolation or wrapping. For interpolation, the neuropils were segmented in several orthoslices of the scanning focal plane (xy). Spherical structures, e.g., AL and glomeruli, were reconstructed by segmentation of each structure around its center in the three focal planes ( $x y, x z, y z)$, and subsequently the wrapping tool of Amira 3.1 was used. As a measure of brain size, the total volume of selected neuropils was calculated [total SN: antennal lobe, medulla, lobula (without lamina), mushroom body, and central complex]. The protocerebrum as a whole was not considered as a comparative volumetric measure because of difficulties in determining its outline close to the SOG.

Selected neuropils of nine brains (queens: $n=3$, males: $\mathrm{n}=3$, and workers $\mathrm{n}=3$ ) were reconstructed. For an additional 11 brains (queens: $n=4$, males: $n=4$, and workers: $n=3$ of different size), the total number and volume of all glomeruli were assessed by complete $A L$ reconstructions.

\section{AL phenotypes}

To address the question of whether a continuous transition or a switch in size of the macroglomerulus exists in the workers' AL, another 31 brains were analyzed. In addition, the ALs of seven large pupae were investigated to examine whether the MG already is present during late developmental stages.

A subset of 8-20 glomeruli at the root of the AN was reconstructed as well as one easily identifiable landmark glomerulus (CG) located separately from the other glomeruli in the coarse neuropil of the AL. In large workers, the subset of glomeruli contained the MG, and the remaining glomeruli were all labeled as SG (satellite glomeruli). In small workers, the glomerulus corresponding to the $M G$ could not be identified based on landmarks but supposedly was also located close to the root of the AN into the AL. Therefore, the largest glomerulus within the subset was labeled as LG (largest glomerulus), and the remaining glomeruli were labeled SG, as in large workers. It has to be noted that the LG of small workers does not necessarily correspond to the MG in large workers.

Because brain size and its components relate to body size, large workers have larger glomeruli compared with small workers. We therefore correlated the volume of the reconstructed glomeruli (MG, LG, CG, or the mean of all $\mathrm{SG}$ ) with the total volume of the $\mathrm{AL}(\mathrm{AV})$. The allometric relationship between glomerulus volume $(\mathrm{GV})$ and $\mathrm{AV}$ was calculated by using the model: $\mathrm{GV}=\mathrm{a} \cdot \mathrm{AV}^{\mathrm{e}}$.

The relationship between body size and AV was assessed by using the measured head width (HW) of all 31 workers. With an iteration method, we obtained the follow- 
ing relationship: $A V \times 10^{6}=1.83 \times H W^{0.80}\left(r^{2}=0.73\right.$, $n=31$ ). A very similar allometry was measured for HW vs. size of selected neuropils: $\mathrm{SN} \times 10^{6}=11.93 \times \mathrm{HW}^{0.80}$ $\left(r^{2}=0,91, n=3\right)$, which indicates that AL volume scales isometric with brain volume. The exponent is $<1$, so large workers (large head width) have relatively smaller brains compared with small workers. The head width as a universal measure of body size allows comparing results from different studies or series of experiments even if brain or $\mathrm{AL}$ volume is inaccessible.

\section{SEM}

Animals were anesthetized with $\mathrm{CO}_{2}$ and decapitated. Heads were fixated with FixMix, washed twice in Aqua dest, and sonicated for 10 minutes. After this cleaning step, heads were dehydrated in an ascending series of ethanol (70\%, 80\%, 90\%, 95\%, and 100\%, 10 minutes each), transferred into acetone (100\%, 10 minutes), and finally dried on filter paper. Samples were glued with superglue onto SEM specimen holders, platinum sputtered (MED0 10; Balzers, Liechtenstein) for 5 minutes (25 mA), and investigated with a Zeiss DSM 962 scanning electron microscope (at $15 \mathrm{kV}$ ).

\section{Image editing}

Confocal image stacks were analyzed with Amira 3.1 (Mercury Computer Systems). Segmentation was performed at full resolution $(1,024 \times 1,024)$, and for the 3D reconstructions the label fields were down sampled $(4 \times$ $4 \times 1)$ and smoothed. The SEM pictures were edited in Adobe Photoshop 7.0 (Adobe Systems Software, Dublin, Ireland) for contrast and brightness adjustment. The background behind the heads (specimen holders) was retouched, and pictures of large heads (queen and soldiers) were stitched from two single pictures.

\section{Calcium imaging}

The procedure for measuring changes in intracellular calcium concentration of AL projection neurons was developed for the honeybee (Sachse and Galizia, 2002). We adapted the technique for ants (Zube et al., 2008) and used a very similar approach in this study. Briefly, large workers were fixed in a Plexiglas stage, a small window was cut into the head capsule, and Fura-2 dextran (F3029; Molecular Probes, Eugene, OR) was applied with a glass electrode into the lateral protocerebrum, aiming for the axons of projection neurons from the AL. After dye application, the brain was protected by a cover with Kwik-Sil (WPI, Sarasota, FL). After at least 4 hours, measurements were taken with an Olympus imaging system (Cell R 2.3), an upright epifluorescent microscope (BX51WI; XLUMP, NA 0.95), and an air-cooled CCD camera (model 848403G; Hamamatsu Photonics, Japan) at a sampling rate of 4
Hz. Data capture and image processing as well as odor application were similar to those described by Zube et al. (2008).

An amount of $5 \mu$ l odor diluted in hexane (Sigma Aldrich, Deisenhofen, Germany) was applied onto a filter paper, and the cartridge was placed into the olfactometer for stimulation. Three different odors, including the two main components of the trail pheromone, were used for stimulation. Both pheromone components, methyl-4methylpyrrole-2-carboxylate (M4MP2C; Sigma Aldrich) and 2-ethyl-3,6-dimethylpyrazine (2E3,6DMP; Oxford Chemicals, Oxford, United Kingdom) were used at a concentration of $10^{-5}$, and, as a general odor, 1-octanol (Sigma Aldrich) was presented at a concentration of $10^{-3}$.

\section{Statistical analysis}

Descriptive statistics and nonlinear regressions were calculated in Statistica 6.1 (StatSoft, Tulsa, OK). Data are plotted with Statistica 6.1, Microsoft Office Excel 2007 (Microsoft Corporation), or Cell R 2.3 (Olympus Corporation, Tokyo, Japan).

\section{RESULTS}

\section{Sexual dimorphism and worker polymorphism (SEM)}

Between queens and males, and also within the workers caste, a great variety of head morphologies was found (Figs. 1A,B, 2A-C). Most conspicuous is the size polymorphism and differences in the shape of the head and the mandibles. The queens' head is almost twice as large as the males' head [HW queen: $4.63 \mathrm{~mm} \pm 0.12(\mathrm{SD}) \mathrm{mm}, \mathrm{n}=$ 6; and $\left.\mathrm{HW}_{\text {male }}: 2.43 \mathrm{~mm} \pm 0.10(\mathrm{SD}) \mathrm{mm}, \mathrm{n}=24\right]$. Males have relatively large eyes and ocelli and more delicate mandibles compared with the other two castes.

Workers exhibit a highly pronounced size polymorphism: The investigated workers' $\mathrm{HW}_{\text {worker }}$ ranged from 0.6 to $4.3 \mathrm{~mm}$, and different morphological characters were observed: Heads of workers with $\mathrm{HW}<3.2 \mathrm{~mm}$ are covered with hairs (setae). Commonly distinguished as minor workers, these ants have slender heads and pointed mandibles, whereas major workers have bulky heads and blunt-tip mandibles. Workers with HW $>3.2 \mathrm{~mm}$ have bald and shiny heads, which separates them morphologically from minor and major workers. These workers are socalled soldiers. Major and minor workers cannot be classified unambiguously because of continuous transitions of body size and other morphological characters. For this reason, we are using the measure HW to discriminate between workers of different sizes.

\section{Selected neuropils of the brain}

Based on confocal images of three brains of each caste, $3 \mathrm{D}$ reconstructions of selected neuropils allowed volumet- 

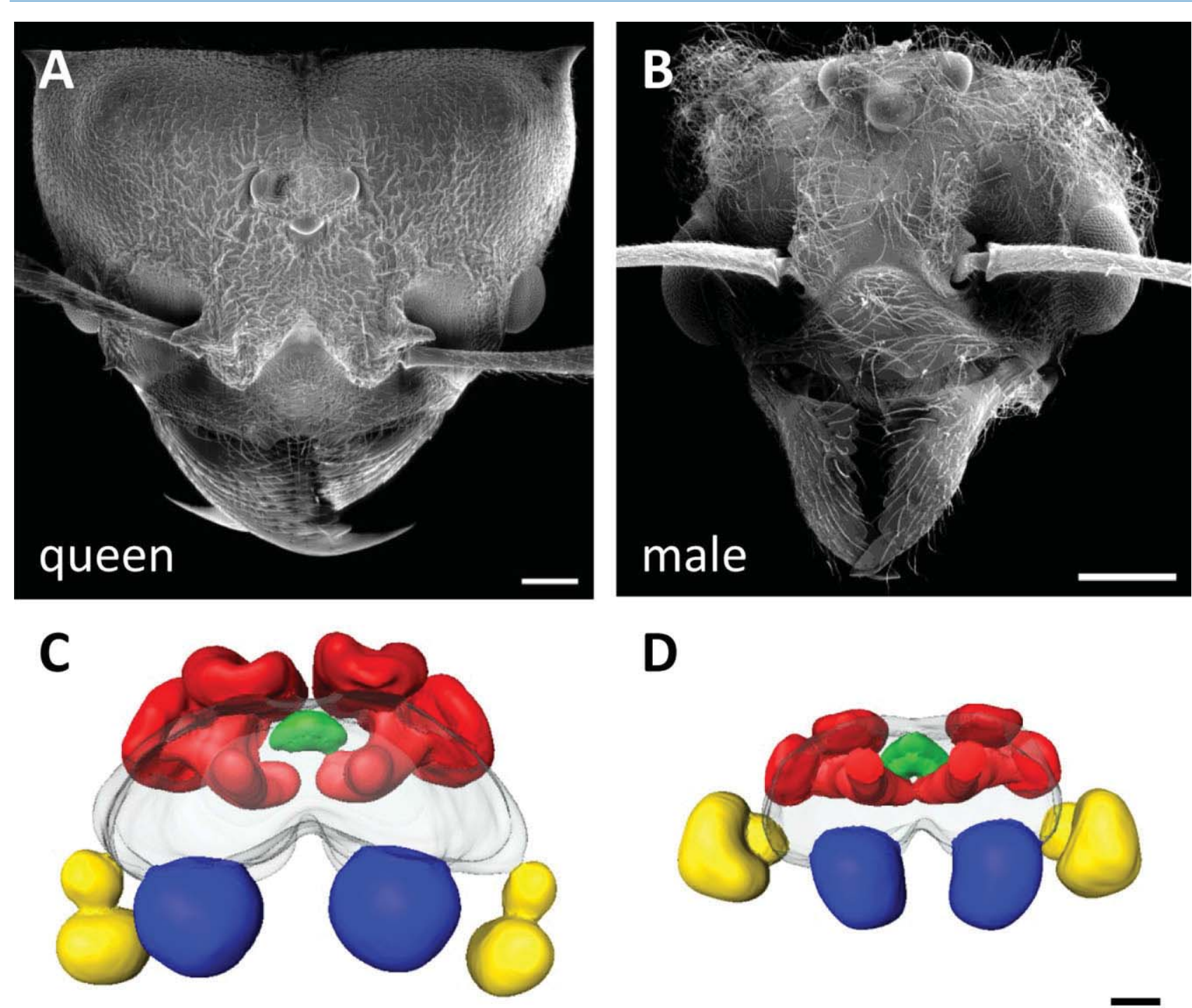

D
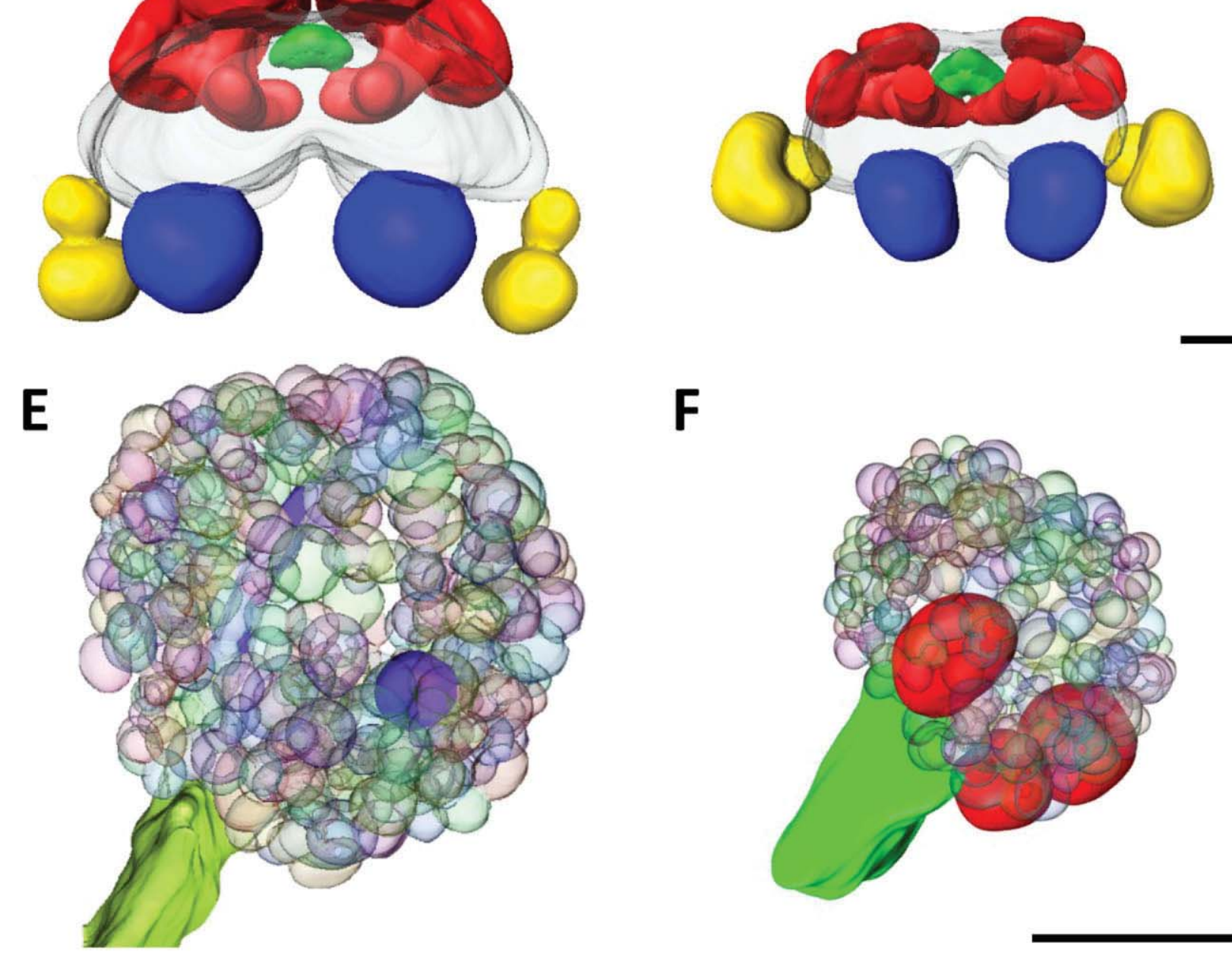

F

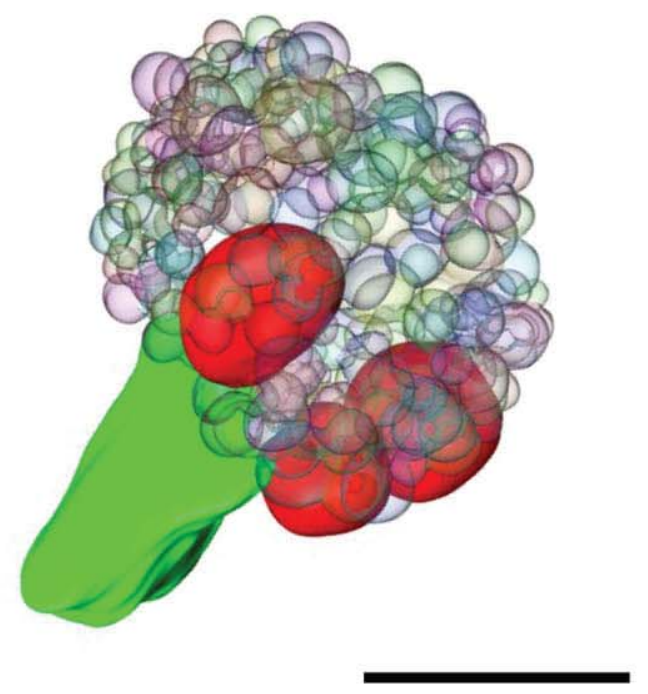

Figure 1 
ric comparisons. As a measure of brain size, the sum of the selected neuropils (total $\mathrm{SN}$ ) was quantified.

The total SN measured for queens is about twice as large as the total SN of males (Table 1, Figs. 1C,D, 3). The ALs in both sexuals contribute substantially to the total SN (31-36\% in queens and $30-37 \%$ in males; Fig. 3). The relative volume of the queens' OLs (17-22\%) is smaller compared with the males' OLs (34-37\%). The relative size of the queens' $C B$ is small (1.2-1.4\%), and it is strikingly large in males, although it contributes only $1.9-3.0 \%$ to the total $\mathrm{SN}$. However, its absolute volume is almost as large as that in the queen (mean 98\%, $n=3$ ). The remaining proportion of the total $\mathrm{SN}$ is occupied by the MBs that are relatively small in males, mainly because of their relatively large OLs. The absolute volumes of males' MBs are in the range of small workers' MBs and are only about $34 \%$ (Table 1, $n=3$ ) of the queens' MBs.

The volume range of the total SN measured in the three workers illustrates again the enormous size polymorphism (Table 1, Figs. 2D-F, 3). As in sexuals, the ALs contribute with $29-40 \%$ substantially to the total SN. The workers' OLs are small, ranging from $2 \%$ in the smallest worker investigated $(\mathrm{HW}=0.64)$ to $9 \%$ in the largest worker $(\mathrm{HW}=3.26)$. As in queens, the workers' CB contributes $1-1.3 \%$ to the total SN. The workers' MBs occupy with more than $50 \%$, the major proportion, of the total SN, and with $67 \%$ this is most pronounced in the brain of the smallest worker.

\section{The $\mathrm{AL}$ in different castes}

To analyze differences in the AL organization across the three castes, we quantified the volume based on complete $3 \mathrm{D}$ reconstruction of all glomeruli within the $\mathrm{AL}$ of four queens, four males, and three workers of different sizes. The numerous glomeruli in all investigated ALs are located

Figure 1. Morphology of the head and anatomy of the brain and the antennal lobes in the two sexual castes in the leaf-cutting ant $A$. vollenweideri (all frontal views; left: queen; right: male). A,B: SEM pictures of the head illustrating the morphological differences in, e.g., shape of the head and the mandibles. C,D: 3D reconstruction of the selected neuropils of the brain and the protocerebrum (transparent). Compared with the queen, the male has conspicuously large optic lobes and a large central body. Antennal lobes (AL): blue; mushroom bodies $(\mathrm{MB})$ : red; optic lobes $(\mathrm{OL})$ : yellow; central body $(\mathrm{CB})$ : green. E,F: 3D reconstruction of all glomeruli within the (right) antennal lobe and its innervations by the antennal nerve (AN, green). The $\mathrm{AL}$ of the queen comprises 344 glomeruli, and one landmark glomerulus located in the coarse neuropils is marked in blue. The AL of the male comprises 246 glomeruli, and three of them are extremely large and are therefore denominated as macroglomeruli (MGs). Scale bars $=500 \mu \mathrm{m}$ in $\mathrm{A}, \mathrm{B} ; 100 \mu \mathrm{m}$ in $\mathrm{D}$ (applies to $\mathrm{C}, \mathrm{D}$ ); $100 \mu \mathrm{m}$ in $\mathrm{F}$ (applies to E,F). in a peripheral layer two or three glomeruli deep surrounding a central (coarse) neuropil.

We found considerably more glomeruli in the queens' ALs (344, 353, 339, 346 glomeruli) than in the males' ALs (246, 241, 238, 244 glomeruli; examples in Fig. 1E,F). The male ALs comprise three glomeruli and the queen ALs one particularly large glomerulus. According to our criteria (see below), only the three large glomeruli in the males' ALs are referred to as macrog/omeruli (MGs; Fig. 4).

Within the worker caste, the counted number of glomeruli (396, 405, and 442 glomeruli; example in Fig. 6B) was higher compared with both queens and males. It seems that there is a high variance in the number of glomeruli within the workers' ALs. However, this aspect was not further investigated in this study.

As was known from our previous study, in large workers one strikingly large glomerulus (MG; Fig. $2 \mathrm{H}, \mathrm{I}$, red) is located close to the root of the AN. With a volume of $22 \times$ $10^{3} \mu \mathrm{m}^{3}$ ( $\mathrm{HW}=2.22 \mathrm{~mm}$ ), the $\mathrm{MG}$ is about 10 times larger than the median of all glomeruli volumes, and a similar measure was found for the MG in a worker with $\mathrm{HW}=3.26$ $\mathrm{mm}$ (nine times). We found the MG already in the ALs of pupae in their late pupal stage ( $n=7$, example in Fig. $2 \mathrm{~K}$ ). The $\mathrm{AL}$ of the small worker investigated ( $\mathrm{HW}<1 \mathrm{~mm}$ ) lacks a prominent glomerulus at the entrance of the AN; instead, the largest glomerulus is located toward the midline (light blue; Fig. 2G,J). With a volume of $4.7 \times 10^{3} \mu \mathrm{m}^{3}$, it is about five times larger than the median of all glomerular volumes. In contrast to the case in large workers with $M G$, the largest glomerulus in the queen's $A L$ is located laterally (light blue; Fig. 2L). With a volume of $28 \times 10^{3}$ $\mu \mathrm{m}^{3}$, it is about six times larger than the median of all glomerular volumes.

\section{Identification of macroglomeruli}

Although we already termed the largest glomerulus in large workers an $M G$, a measure to separate a large glomerulus from an MG is so far missing. We used the volumes and descriptive statistics of all glomeruli reconstructed in the three workers' ALs to obtain a quantitative measure of whether the largest glomerulus is an outlier with respect to the variance of glomerular volumes found in the AL. Because the size distribution of glomerular volumes in the $\mathrm{AL}$ is skewed to smaller volumes, the standard deviation as a measure of variance could not be used. Instead, we identified outliers, which are values distant from the rest of the data by the interpercentile range, with outlier $>a_{U}+k \cdot\left(Q_{U}-Q_{L}\right)$, where $\mathrm{O}_{\mathrm{L}}$ is the lower percentile, $\mathrm{O}_{U}$ the upper percentile, and $k$ the outlier criterion. We set $k=3$, which is very conservative (commonly 1.5 is used; Sachs, 1988), and defined outliers as MG based on their extreme volume compared with the rest of the data (Fig. 4). Based 

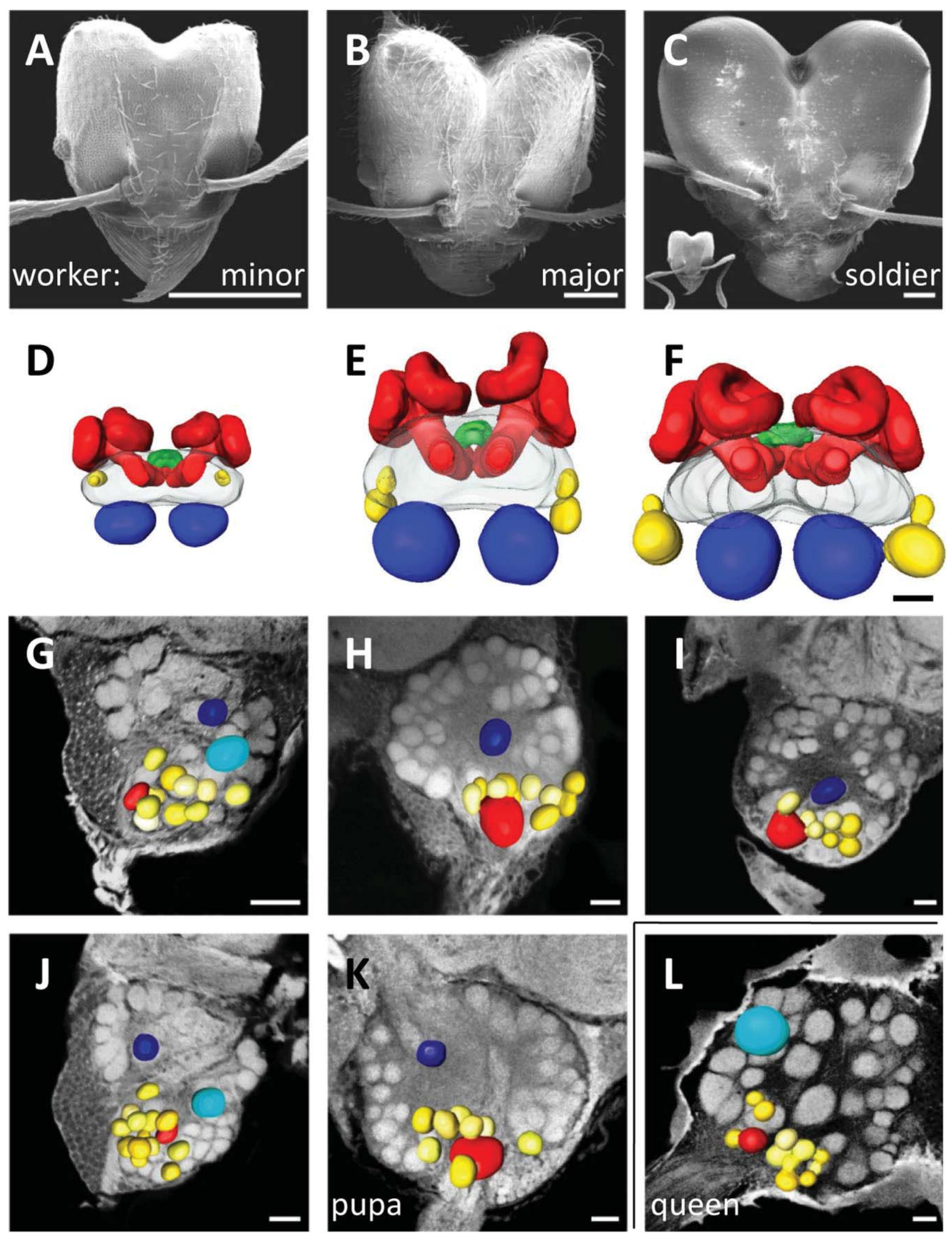

Figure 2 
TABLE 1.

Absolute Volumes of Selected Neuropils in the Three Castes ${ }^{1}$

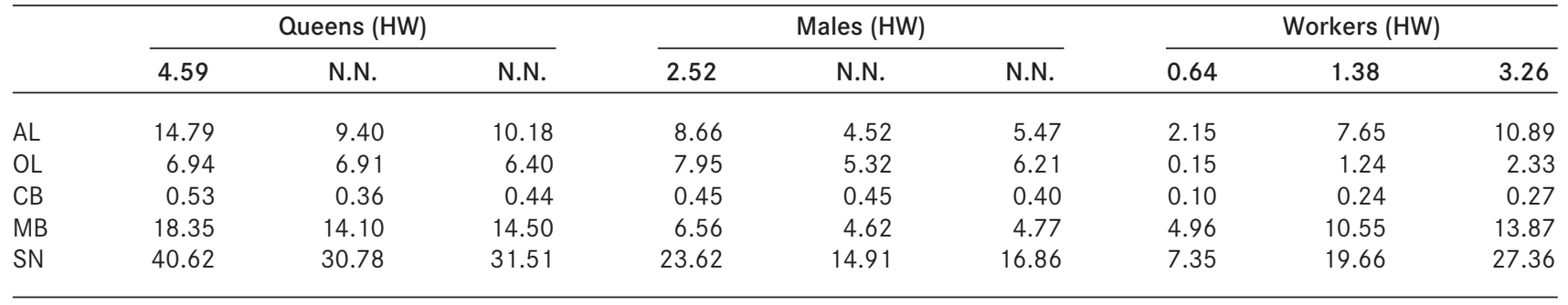

${ }^{1}$ Absolute volumes of selected neuropils (in $\mu \mathrm{m}^{3} \times 10^{6}$ ) measured in three specimens for each caste. The relative volumes of each neuropil are shown in Figure 3 for each specimen. HW, head width in millimeters (N.N., no data available); AL, antennal lobe; OL, optic lobes; CB, central body; MB mushroom body; $\mathrm{SN}$, total volume of selected neuropils.

on this criterion, three large glomeruli in the male $A L$ and the large glomerulus in the $\mathrm{AL}$ of large workers classify as MG. Queens do possess large glomeruli; however, with reference to the variance of glomerular volumes, the largest glomeruli are not considered as outliers.

\section{AL phenotypes in workers}

The disproportional allometry of the MG and its corresponding glomerulus in small workers indicates that possibly two distinct AL phenotypes (with and without MG) exist. Therefore, we addressed the question of whether the size of the MG varies continuously across workers of different size by analyzing the ALs of another 31 workers ranging from HW 0.6 to $4.3 \mathrm{~mm}$. The five largest workers (HW > $3.2 \mathrm{~mm}$ ) could be classified as soldiers, because their heads were bald.

A subset of 8-20 glomeruli in the $\mathrm{AL}$, located close to the root of the AN, were reconstructed (red and yellow glomeruli; Fig. 2G-J). In all investigated ALs of workers, a landmark glomerulus (CG, dark blue; Fig. 2G-K) positioned in the coarse neuropil of the AL could be identified and was used as additional size reference for the MG. In large workers, the subset of glomeruli contained the MG (red; Fig. $2 \mathrm{H}, \mathrm{I})$. In small workers, the largest glomerulus was found at various positions within the subset and was labeled as LG (red; Fig. 2G,J).

To quantify the relation between $A L$ volume $(A V)$ and glomerular volume (GV), we calculated in an iterative approximation (least-squares method) the regression by using the model: $G V=a \cdot A V^{e}$. The landmark glomerulus CG and the mean volume of the SG are almost isometric to the volume of the AL (Fig. 5; e $=1.29$ and $\mathrm{e}=0.82$ respectively, both $P<0.05$; Levenberg-Marquardt algorithm). A sharp transient in the relative size of the largest glomerulus at the root of the AN divides the group of workers: workers without an MG (HW = $0.98 \mathrm{~mm}$; small workers) and workers with an MG (HW = $1.19 \mathrm{~mm}$; large workers). In large workers $(n=22)$, the $M G$ is isometric to the $A L$ volume (e = 1.06, $P<0.05$; Levenberg-Marquardt algorithm). In small workers ( $\mathrm{n}=9$ ), no correlation between AV and volume of LG was found $(P=0.15$; LevenbergMarquardt algorithm).

Workers separate into two neuroanatomical subcastes based on a neuroanatomical trait. Our analysis revealed two AL phenotypes, either with MG (MG phenotype) or with regular-sized glomeruli at the root of the AN (RG phenotype). None of the morphological measures often used to discriminate minors and majors is as distinct as this neuroanatomical trait of the $\mathrm{AL}$.

Figure 2. Morphology of the head and anatomy of the brain and the antennal lobes in workers of different size (all frontal views). A-C: SEM pictures of the head illustrating the morphological differences in head shape and the enormous size difference within the worker caste. As size comparison, the minor worker is shown scaled as an inset in C. D-F: Scaled 3D reconstruction of the selected neuropils of the brain and the protocerebrum (transparent) in workers of different size. Leaf-cutting ant workers have relatively large antennal lobes. Brain size is correlated with body size: the small worker $(\mathrm{HW}=0.64 \mathrm{~mm})$ has a much smaller brain compared with large workers $(\mathrm{HW}=1.36 \mathrm{~mm}$ and $3.26 \mathrm{~mm})$. Antennal lobes (AL): blue; mushroom bodies (MB): red; optic lobes (OL): yellow; central body (CB): green. G-L: Confocal micrographs (orthoslices) of the (right) ALs with a subset of 3D-reconstructed glomeruli. Large workers (HW $>1 \mathrm{~mm} ; \mathrm{H}, \mathrm{I}, \mathrm{K})$ contain a macroglomerulus (MG, red in $\mathrm{H}, \mathrm{I})$, and the MG is already present at a late developmental stage (pupa of a large worker; MG, red in K). In small workers (HW $<1 \mathrm{~mm}$; G,J), the position of the largest glomerulus (LG, red in G,J) within a subset of glomeruli (satellite glomeruli, SGs, yellow in G-L) close to the root of the AN varies, and the position of the largest glomerulus within the AL is toward the midline of the brain (light blue in G,J). As a comparison with workers, the largest glomerulus in the AL of the queen is at a lateral position (light blue in L). A landmark glomerulus (CG, dark blue in G-K) that could be identified in all workers based on its location in the coarse neuropil was used as a reference glomerulus for allometric measures. Scale bars $=500 \mu \mathrm{m}$ in A-C; $100 \mu \mathrm{m}$ in $\mathrm{F}$ (applies to D-F); $50 \mu \mathrm{m}$ in $\mathrm{G}-\mathrm{L}$. 


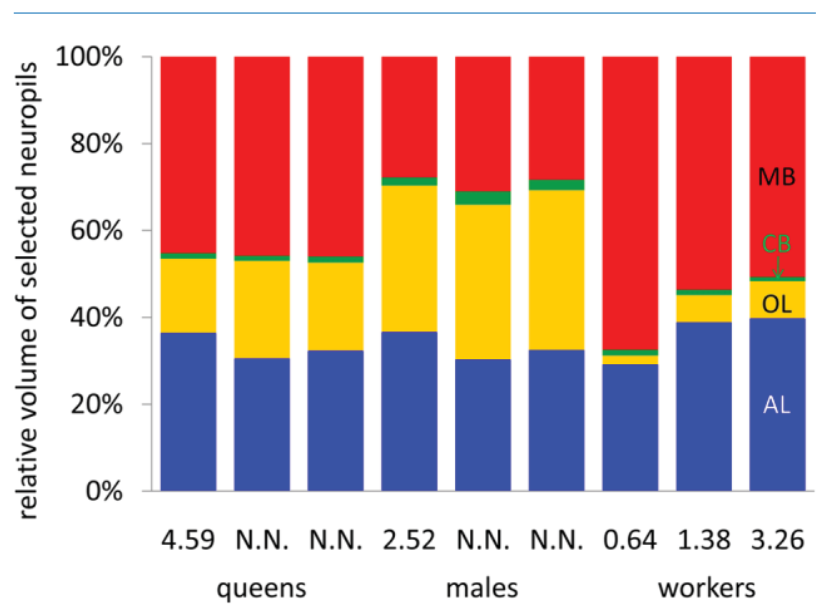

Figure 3. Relative volume of the selected neuropils measured for three individuals of each caste. Both ALs occupy a large proportion of the total SN $(29-40 \%)$. In queens and especially in males, the OLs are relatively large (17-22\% and $34-37 \%$, respectively), and consequently the relative proportion of the MBs is small. In workers, the OLs are in the range of $2-9 \%$ of the total SN volume, and, with $1-1.3 \%$, the $C B$ contributes only little to the total $S N$ volume. In contrast, the $\mathrm{CB}$ in males measures almost $1.9-3.0 \%$ and is larger even in absolute measure compared with the $C B$ in the large workers. Numbers on abscissa indicate the head width (HW) of the investigated individuals.

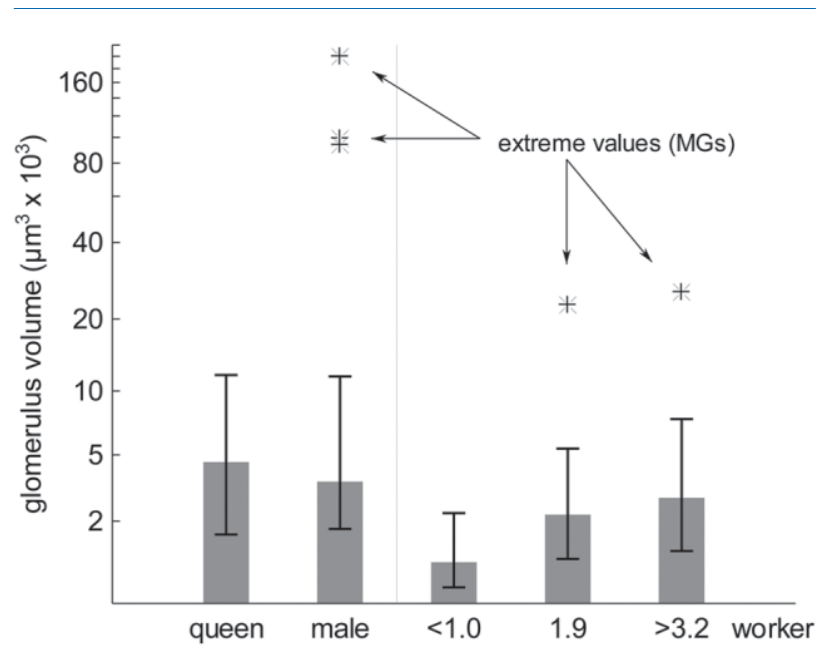

Figure 4. Descriptive statistics as a measure to identify an MG. Median and variance of all glomerular volumes in the ALs of one queen (as an example of three investigated), one male (as an example of three investigated), and three different-sized workers. The number of glomeruli was 344 in the queen's; 346 in the male's; and 396, 405, and 442 glomeruli in the workers' ALs. A conservative outlier coefficient $(O C=3)$ was used to identify MGs, which are indicated with an asterisk. The males' ALs contain three MGs. In the ALs of large workers (HW > $1 \mathrm{~mm}$ ), a single MG was found, whereas the AL of the small worker investigated contained no MG. Bars indicate the median volume of glomeruli, and whiskers indicate the range of glomerular volumes (5-95\%). Note the log scale on the $y$-axis used to plot the large variance of glomerular volumes. X-axis: HW of investigated specimens in millimeters.

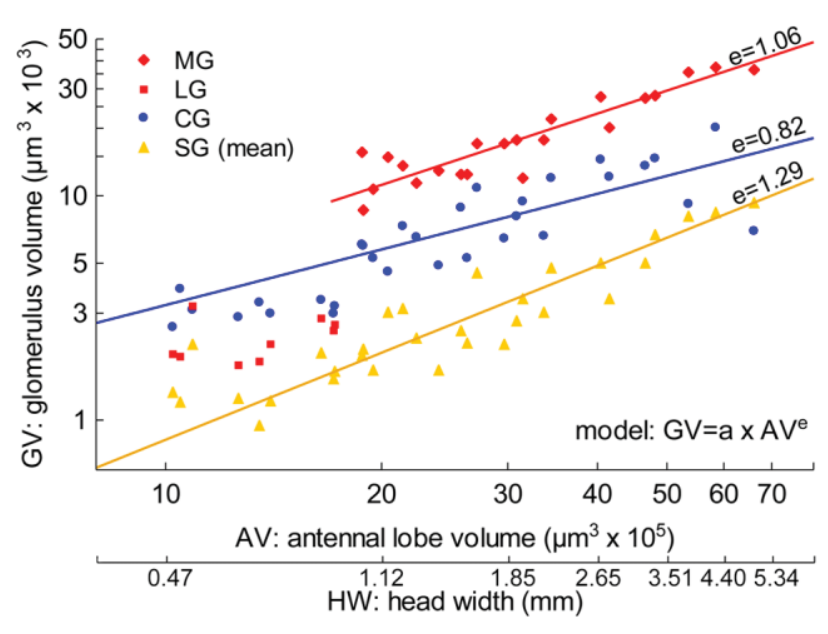

Figure 5. Distinct AL phenotypes in the workers' AL revealed by the diphasic allometry of the MG and the corresponding glomerulus in small workers. The volume of different glomeruli is related to the volume of the AL. The largest glomerulus at the root of the AL is shown in red. In large ALs (large workers; HW $=1.19 \mathrm{~mm}$ ), this glomerulus is an $M G$ with an isometric allometry to the $\mathrm{AL}$ volume ( $=1.1$ ). In small ALs (volume $<2 \times 10^{7} \mu \mathrm{m}^{3} ; \mathrm{HW}=0.98 \mathrm{~mm}$ ), the largest glomerulus (LG) is relatively small in comparison with the MG, and no significant correlation between AL volume and $L G$ volume was found. One landmark glomerulus (CG, blue), and the mean volume of the satellite glomeruli (SG, yellow) show isometric allometry to the $\mathrm{AL}$ volume ( $\mathrm{e}=0.8$ and 1.3 , respectively).

\section{Function of the MG in workers}

Successful preparation and staining with the calciumsensitive dye Fura2-dextran were indicated by spontaneous (without odor stimulation) changes in fluorescence (activity regions) in the $\mathrm{AL}$ of six large workers ( $1 \mathrm{~mm}<<$ $\mathrm{HW}<3.2 \mathrm{~mm}$ ). The size of these activity regions was approximately the size of single glomeruli. Because of the low optical resolution at the focal depth, single glomeruli could not be identified. We focused, based on our neuroanatomical data for large workers, at a depth of $30 \mu \mathrm{m}$ below the apical (anterior) surface of the AL, where we expected the MG location to be. Stimulation with the releaser component of the trail pheromone (M4MP2C) evoked a strong calcium signal (change in fluorescence $>2 \%$ ) close to the AN and toward the midline (Fig. 6C,D). The size and position of the activity region in response to M4MP2C (diameter $\sim 40 \mu \mathrm{m}$ ) correspond very well to those of the MG. Stimulation with the second main component of the trail pheromone (2E3,6DMP) evoked activity in an adjacent region, toward the midline but somewhat overlapping with the putative MG (Fig. 6E,F). Activity was recorded only in the two regions described above, and the remaining field of view of the $A L$ did not show any activity in response to stimulation with the releaser component of the trail pheromone. 

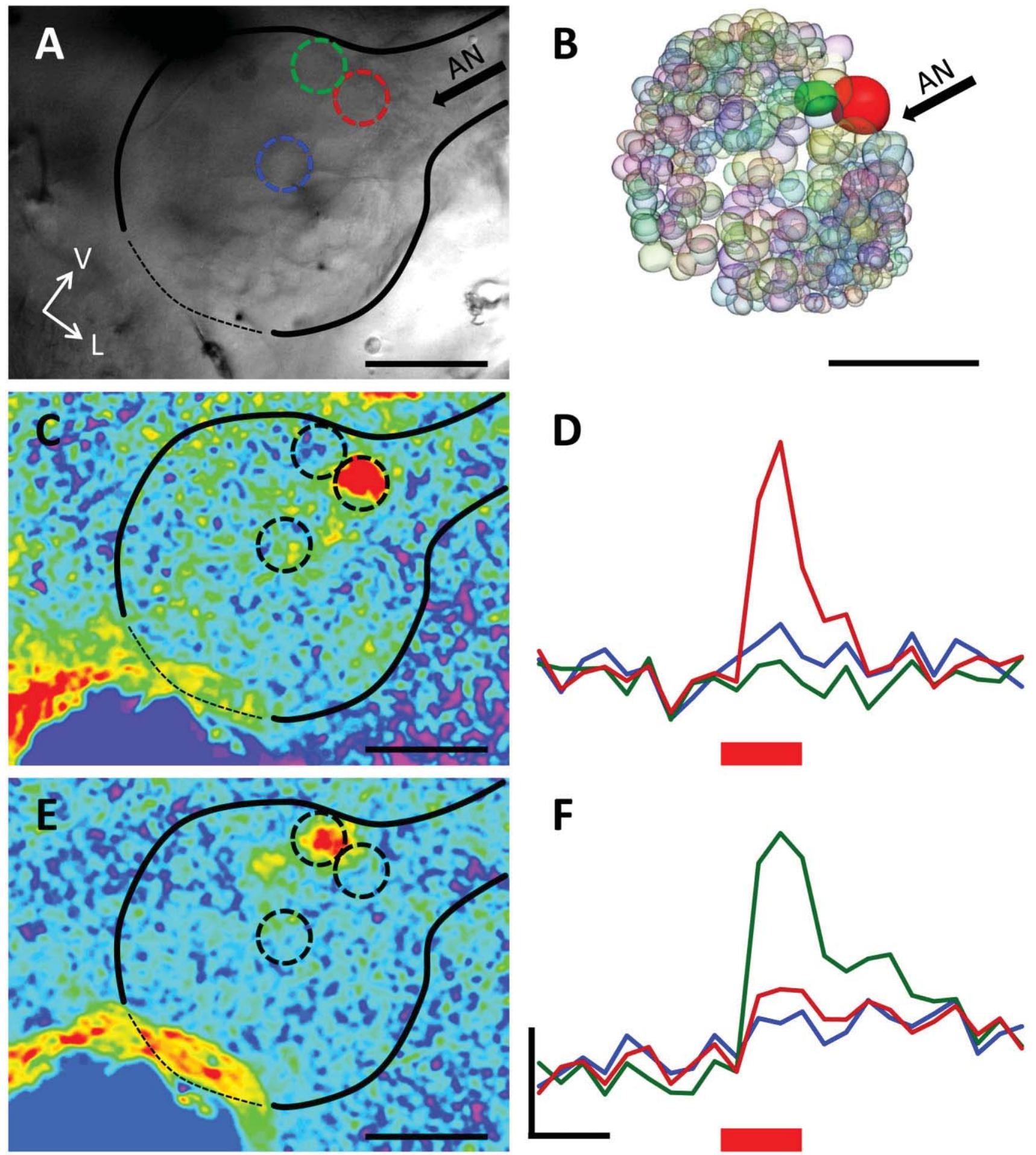

Figure 6. Example of neuronal activity measured in the AL in response to stimulation with the releaser component of the trail pheromone (M4MP2C). A: Ratiometric picture $(340 \mathrm{~nm} / 380 \mathrm{~nm}$ ) of the AL (outlined in black) and the regions of interest (ROls, colored circles, diameter $40 \mu \mathrm{m})$ that were selected to analyze the fluorescence change across the total recording duration (6 seconds). Note that the many and small glomeruli can barely be discriminated at this focal plane ( $\sim 30 \mu \mathrm{m}$ below the surface of the AL). B: To illustrate the orientation of the AL during Ca imaging, a 3D reconstruction of the AL from a different worker $(\mathrm{HW}=1.96 \mathrm{~mm})$ is shown. The $\mathrm{MG}$ in this reconstruction has a diameter of about $40 \mu \mathrm{m}$. C,D: False-color-coded picture of the AL $500 \mathrm{msec}$ after stimulus onset. The region where the MG is expected, close to the root of the AN, shows high neuronal activity upon stimulation with M4MP2C (C). The size of the activity region corresponds well to the size of the MG. A region adjacent to this activity region (toward the midline) shows high neuronal activity upon stimulation with 2EDMP (D). E,F: Temporal dynamic of the calcium response to stimulation with M4MP2C (E) and 2EDMP (F). Only at the region where the MG is expected (red circle in A) was a strong calcium response measured upon stimulation with M4MP2C. No response was observed in the two reference ROIs (green and blue circles in A). Data are slope corrected, and stimulation is indicated by the red bar. Vertical scale: $1 \%$ change in fluorescence. Scale bars $=100 \mu \mathrm{m}$ in A-C,E; 1 second in F (applies to D,F). 


\section{DISCUSSION}

We studied the glomerular organization of the $\mathrm{AL}$ in the three castes of the leaf-cutting ant $A$. vollenweideri. Male ALs differ greatly from the queen's ALs according to glomerular organization, and our comprehensive investigation of the worker caste revealed a pronounced trait variation.

We found within the male caste three extremely large glomeruli (MG) that provoke the assumption that for males at least three pheromone components may be important for nuptial flight, courtship, and mating behavior. Queens have only one large glomerulus with unknown function, and its size is less pronounced compared with the MG of the two other castes (males and workers). The MG in large workers divides the caste into two distinct AL phenotypes. The phenotype with MG (MG phenotype) was found in large workers, whereas the other phenotype with only regularsized glomeruli (RG phenotype) was found in small workers. We propose, based on functional imaging data (calcium imaging) of the $\mathrm{AL}$, a prominent role of the $\mathrm{MG}$ for information processing of the trail pheromone. We conclude that the trait variation within the $\mathrm{AL}$ of workers leads to alternative processing of odor information and presumably represents the neuronal basis of known differences in trail-following behavior (Kleineidam et al., 2007). This in turn promotes division of labor within the colony by supporting workers' task allocation on, e.g., foraging trails.

\section{Dimorphisms in the sexual castes}

The head morphology of males illustrates apparent adaptations for visual orientation: large, complex eyes and ocelli. Mating with a queen is the essential challenge for males, and, since this takes place in air, visual cues are probably very important. The high selective pressure on visual skills, in particular, at low light intensities, is exemplified by larger eyes in species that have their nuptial flights at night compared with species mating during daytime or at dawn (Moser et al., 2004).

We compared the brain anatomy among the three castes based on 3D reconstructions of selected neuropils and found substantial differences. Structural plasticity of neuropil volumes (e.g., experience-dependent plasticity) may further influence the volume of neuropils, as was shown for ants (Gronenberg et al., 1996; Kuhn-Buhlmann and Wehner, 2006). However, such plasticity is in a limited range compared with the volumetric differences found for, e.g., sexuals in this study.

The gross anatomy of the brain confirms the conclusion drawn from the male's head morphology. The optic lobes (OLs) are relatively large compared with other selected neuropils measured. The relative size of modality-specific neuropils reflects the importance of the corresponding sensory modality for behavior. This correlation between neuropil size and behavioral performance is demonstrated for many insects, particularly for ants (Gronenberg, 2008).

The central body (CB) is conspicuously large in males. The absolute volume is almost as large as the CB in queens, although the brain volume of males is only about half the size. The $\mathrm{CB}$ is known to play a significant role in higher locomotion control and orientation (Homberg, 2008; Strauss, 2002). It seems that orientation during nuptial flight poses high demands on the functional unit for locomotion control.

In contrast, the mushroom bodies (MBs) of males are comparably small. Multimodal information is processed in the MBs, and it is known to be of great significance for learning and memory (Heisenberg, 2003; Strausfeld et al., 2009). Both the long-living queen and the workers show rich behavioral repertoires and adaptive behavior in many different contexts (Camargo et al., 2007). Successful queens live for several years together with up to 20 millions of workers in a mature nest (Lofgren and Vander Meer, 1986). In contrast, males probably have to rely more on innate behavior than on flexible, learning-based behavior because of their short life span and limited opportunities for mating.

\section{The ALs}

The ALs are the largest sensory neuropils in the brains of all three castes and contribute with $29-40 \%$ to the total volume of the selected neuropils. The sense of smell is the most prominent sensory modality for the majority of ants, and this again is reflected in the size of the ALs.

The number of glomeruli counted in queens' ALs exceeds by far the number found in males' ALs (346 vs. 242 glomeruli/AL). Similar sexual dimorphism has been described for other ant species as well (Hoyer et al., 2005; Nishikawa et al., 2008; Zube and Rössler, 2008). The size of a glomerulus depends on the number of terminating ORNs expressing the same OR gene. Large glomeruli have been described for the ALs of males of other ant species as well, and in some cases even the term MG has been used, unfortunately without reference to the variance of glomerular volumes (Hoyer et al., 2005; Nishikawa et al., 2008; Zube and Rössler, 2008). For a number of moth species, large glomeruli are known that process information about sex pheromone components. These glomeruli are always located at the entrance of the antennal nerve (AN), often in a so-called macroglomerular complex (MGC; Anton and Homberg, 1999). Highly specific olfactory receptor neurons tuned to one or few components of the sex pheromone innervate the MG in moth. The odor specificity of the corresponding ORNs of the MG in leaf-cutting ant males is unknown. We suggest that three different components of the sex pheromone play a prominent role for male behavior. However, little is known about the pheromone commu- 
nication between queens and males prior to and during nuptial flights, and further investigation is needed

\section{Phenotypic trait variation in workers}

For workers we counted a variable but even higher number of glomeruli compared with queens. Founding queens have to perform most of the workers' tasks early in colony life, and this includes foraging for suitable substrate for the fungus, care taking for fungus and offspring, and nest building and defense. Our expectation was therefore that the number of glomeruli in the workers' ALs would be the same as or possibly even less than the number in the queens' ALs. However, the opposite is the case. We counted between 396 and 442 glomeruli in the ALs of three different-sized workers, and this variance possibly is related to body size. This question remains to be addressed in future studies.

\section{AL phenotypes}

In an earlier paper, we described a disproportional allometry of glomerular volumes in the ALs of workers of two leaf-cutting ant species (Kleineidam et al., 2005). We show here in our comparative study of many workers that the size variation of the largest glomerulus (MG) is discontinuous across workers of different size and results from distinct developmental patterns.

The MG-corresponding glomerulus in small workers cannot be identified based on its size. For another hymenopteran species, the honeybee, it has been shown that each glomerulus is innervated by a single ORN type, and the spatial position of glomeruli is species specific and conserved across individuals (Galizia et al., 1998, 1999; Kelber et al., 2006). We selected a number of glomeruli within the region of the AL where the MG is located in large workers. The largest glomerulus in this subset is assumed to be homologous to the MG of large workers. We observed the largest glomerulus of this subset at different positions with respect to the root of the AN and not necessarily at the exact same position as the MG in large workers.

The worker phenotype with an MG (MG phenotype) was found only in large workers, whereas the phenotype with regular-sized glomeruli (RG phenotype) was found only in small workers. The MG is formed as a discrete developmental pattern already during pupal development, and such discontinuous phenotypic plasticity is termed polyphenism (Nijhout, 2003). The principal hormones that control polyphenic development are ecdysone and juvenile hormone, and either the pattern of hormone secretion or the pattern of hormone sensitivity in different tissues is altered (Nijhout, 1999; Suzuki and Nijhout, 2008). For the development of polymorphic ant workers, the juvenile hormone titer has a determining function, resulting in sub- castes, e.g., soldiers in Pheidole (Wheeler and Nijhout, 1983, 1984), and probably has also a regulatory function in the development of the MG and RG phenotypes in leafcutting ants. Interestingly, juvenile hormone also plays an important role for division of labor (age polyethism) during adult life in honeybees (Whitfield et al., 2006).

\section{Function of the MG}

We propose, based on functional imaging data, that the MG plays a prominent role in the processing of trail pheromone information. We selectively stained neurons (projection neurons) that relay the $\mathrm{AL}$ to secondary olfactory centers, the calyces of the MBs, and the lateral horn of the protocerebrum (Abel et al., 2001; Kirschner et al., 2006; and our data, not shown). Thus, we measured the output of the AL following odor stimulation. Successful loading of neurons with the Casensitive dye and vital preparations were rare but easy to recognize because of spontaneous activity measured across the entire surface of the AL. In our preparation, the MG is located at a focal depth of approximately $30 \mu \mathrm{m}$ below the anterior surface of the AL. Prior to the recordings, we focused to the estimated position of the MG; however, because of widefield epifluorescent illumination, the outlines of glomeruli could not be identified.

We measured distinct calcium signals in the AL in response to three different odors. After odor stimulation with the releaser component of the trail pheromone (M4MP2C), a single activity region at a medial position close to the AN (AN) was measured. This activity region was similar in size and location to the MG. Unfortunately, the optical resolution of our calcium imaging system (with CCD camera) precluded us from identifying the MG based on its outline. For this aim, a technique with a high optical resolution would be necessary, e.g., two-photon imaging.

The releaser component M4MP2C is sufficient to elicit trail-following behavior. In particular, M4MP2C and also the second main component 2E3,6DMP of the trail pheromone are found in relatively high quantities in the poison gland secretion of several Atta species (Morgan, 2009). The ratio of both defines species specificity (Evershed and Morgan, 1983; Morgan et al., 2006). Interestingly, $2 \mathrm{E} 3,6 \mathrm{DMP}$ is represented in at least one glomerulus further toward the midline but adjacent to the MG. A closely related Atta species (A. sexdens) uses 2E3,6DMP as releaser component of the trail pheromone. In a former comparative study of $A$. vollenweideri and $A$. sexdens (Kleineidam et al., 2005), we found the spatial location of the MG in $A$. sexdens at the location corresponding to where we measured neuronal activity to $2 \mathrm{E} 3,6 \mathrm{DMP}$ in the present study.

What is the physiological significance of an MG? We suggest two possibilities. 1) The detection threshold is lowered by a large number of ORNs. 2) The impact on the 
network of the $A L$ and thereby on the combinatorial code of the projection neurons is increased.

With regard to the first possibility, the detection threshold is given by the properties of the receptor neurons and how the signal from the ORNs is analyzed at the next level of neuronal processing. Compared with the response of the ORNs, in the projection neurons of the $A L$ an improved signal-to-noise ratio has been demonstrated (Bhandawat et al., 2007). Behavioral analysis of bumble bees show that the antennal sensitivity to odors increases with body size (Spaethe et al., 2007). Large leaf-cutting ants have a higher trail fidelity than small workers (Morgan et al., 2006), and in a behavioral study we found workers with MG to be more sensitive to the releaser component of the trail pheromone (unpublished data).

With regard to the second possibility, the impact of any glomerulus on the combinatorial code of projection neurons is given by the interconnection between glomeruli in the $\mathrm{AL}$ network. Many local interneurons (LNs) innervate all or most glomeruli homogeneously, and for honeybees large numbers of heterogeneous LNs have been described (Abel et al., 2001; Fonta et al., 1993; Sun et al., 1993). The heterogeneous LNs probably provide a more specific interaction between glomeruli (Galizia and Szyszka, 2008). If the MG is innervated not only by more ORNs but also by a larger number of LNs and projection neurons, then their contribution to the combinatorial code is increased. We propose that the releaser component is overrepresented in the combinatorial code of projection neurons in MG-phenotype workers. RG-phenotype workers are probably less sensitive to the releaser component of the trail pheromone than MG-phenotype workers; however, the RG phenotype possibly is advantageous in assessing the conspecific mixture of all components of the trail pheromone. Indeed, a behavioral study shows that small workers perform better than large workers when two similar pheromone trails have to be discriminated (Kleineidam et al., 2007).

Our study describes the glomerular organization of the $\mathrm{AL}$ in leaf-cutting ants. We found a highly pronounced sexual dimorphism in the number of glomeruli. Three extremely large glomeruli in males most probably present adaptations for sex pheromone communication. For workers we found a polyphenism in the $A L$ with two distinct $A L$ phenotypes. We propose, based on our functional data, a prominent role of the workers' MG for information processing of the trail pheromone. Trait variation within the $A L$ of workers leads to alternative processing of odor information and presumably represents the neuronal basis of known differences in trail-following behavior. Developmental plasticity in the organization of a neuropil sets the neuronal frame for alternative behavioral phenotypes and thus is an important, and little explored, mechanism underlying division of labor in social insects.

\section{ACKNOWLEDGMENTS}

We thank F. Roces and W. Rössler for encouraging advice and helpful discussions in the course of this study. We are indebted to Alejandro Di Giácomo, Reserva Ecológica “El Bagual” (Alparamis SA, Aves Argentinas), Formosa, Argentina, and the Götz family for providing facilities and friendly support during fieldwork as well as to Nestor Sucunza (Parque Nacional Río Pilcomayo, APN, Formosa) and Paula Cichero (DRNEA, Parques Nacionales) for the permission to work in protected areas and for logistical support. We also thank K. Möller for expert technical assistance and A. Gerber-Kurz and A. Laudahn for their care of the leaf-cutting ant colonies at the University of Würzburg. We thank two anonymous reviewers for their comments on the manuscript.

\section{LITERATURE CITED}

Abel R, Rybak J, Menzel R. 2001. Structure and response patterns of olfactory interneurons in the honeybee, Apis mellifera. J Comp Neurol 437:363-383.

Anton S, Homberg U. 1999. Antennal lobe structures. In: Hansson BS, editor. Insect olfaction. Heidelberg: Springer. p 97-124.

Arnold G, Masson C, Budharugsa S. 1985. Comparative study of the antennal lobes and their afferent pathway in the worker bee and the drone (Apis mellifera). Cell Tissue Res 242:593- 605.

Beshers SN, Fewell JH. 2001. Models of division of labor in social insects. Annu Rev Entomol 46:413-440.

Bhandawat V, Olsen SR, Gouwens NW, Schlief ML, Wilson RI. 2007. Sensory processing in the Drosophila antennal lobe increases reliability and separability of ensemble odor representations. Nat Neurosci 10:1474-1482.

Camargo RS, Forti LC, Lopes JFS, Andrade APP, Ottati ALT. 2007. Age polyethism in the leaf-cutting ant Acromyrmex subterraneus brunneus Forel, 1911 (Hym., Formicidae). J Appl Entomol 131:139-145.

Clyne PJ, Certel SJ, de Bruyne M, Zaslavsky L, Johnson WA, Carlson JR. 1999. The odor specificities of a subset of olfactory receptor neurons are governed by Acj6, a POU-domain transcription factor. Neuron 22:339-347.

Couto A, Alenius M, Dickson BJ. 2005. Molecular, anatomical, and functional organization of the Drosophila olfactory system. Curr Biol 15:1535-1547.

de Bruyne M, Baker TC. 2008. Odor detection in insects: volatile codes. J Chem Ecol 34:882-897.

Dobritsa AA, van der Goes van Naters W, Warr CG, Steinbrecht RA, Carlson JR. 2003. Integrating the molecular and cellular basis of odor coding in the Drosophila antenna. Neuron 37:827-841.

Evershed RP, Morgan ED. 1983. The amounts of trail pheromone substances in the venom of workers of four species of attine ants. Insect Biochem 13:469-474.

Fishilevich E, Vosshall LB. 2005. Genetic and functional subdivision of the Drosophila antennal lobe. Curr Biol 15:15481553.

Fonta C, Sun XJ, Masson C. 1993. Morphology and spatial distribution of bee antennal lobe interneurons responsive to odors. Chem Senses 18:101-119.

Galizia CG, Szyszka P. 2008. Olfactory coding in the insect brain: molecular receptive ranges, spatial and temporal coding. Entomol Exp Appl 128:81-92.

Galizia CG, Nägler K, Hölldobler B, Menzel R. 1998. Odour coding is bilaterally symetrical in the antennal lobes of honeybees (Apis mellifera). Eur J Neurosci 10:2964-2974. 
Galizia CG, Sachse S, Rappert A, Menzel R. 1999. The glomerular code for odor representation is species specific in the honeybee Apis mellifera. Nat Neurosci 2:473-478.

Goll W. 1967. Strukturuntersuchungen am Gehirn von Formica. Z Morphol Okol Tiere 59:143-210.

Gronenberg W. 2008. Structure and function of ant (Hymenoptera: Formicidae) brains: strength in numbers. Myrmecol News 11:25-36.

Gronenberg W, Liebig J. 1999. Smaller brains and optic lobes in reproductive workers of the ant Harpegnathos. Naturwissenschaften 86:343-345.

Gronenberg W, Heeren S, Hölldobler B. 1996. Age-dependent and task-related morphological changes in the brain and the mushroom bodies of the ant Camponotus floridanus. J Exp Biol 199:2011-2019.

Hallem EA, Fox AN, Zwiebel LJ, Carlson JR. 2004. Olfactionmosquito receptor for human-sweat odorant. Nature 427: 212-213.

Hansson BS, Anton S. 2000. Function and morphology of the antennal lobe: new developments. Annu Rev Entomol 45:203-231.

Heisenberg M. 2003. Mushroom body memoir: from maps to models. Nat Rev Neurosci 4:266.

Hildebrand JG, Shepherd GM. 1997. Mechanisms of olfactory discrimination: converging evidence for common principles across phyla. Annu Rev Neurosci 20:595-631.

Hölldobler B, Wilson EO. 1990. The ants. Cambridge, MA: Harvard University Press. 732 p.

Homberg U. 2008. Evolution of the central complex in the arthropod brain with respect to the visual system. Arthropod Struct Dev 37:347-362.

Homberg U, Christensen T, Hildebrand JG. 1989. Structure and function of the deuterocerebrum in insects. Annu Rev Entomol 34:477-501.

Hoyer SC, Liebig J, Rössler W. 2005. Biogenic amines in the ponerine ant Harpegnathos saltator: serotonin and dopamine immunoreactivity in the brain. Arthropod Struct Dev 34:429 - 440.

Hughes WOH, Boomsma JJ. 2007. Genetic polymorphism in leafcutting ants is phenotypically plastic. Proc R Soc Lond B Biol Sci 274:1625-1630.

Joerges J, Küttner A, Galizia GC, Menzel R. 1997. Representation of odours and odour mixtures visualized in the honeybee brain. Nature 387:285-288.

Kelber C, Rössler W, Kleineidam CJ. 2006. Multiple olfactory receptor neurons and their axonal projections in the antennal lobe of the honeybee Apis mellifera. J Comp Neurol 496:395-405.

Kirschner S, Kleineidam CJ, Zube C, Rybak J, Grunewald B, Rössler W. 2006. Dual olfactory pathway in the honeybee, Apis mellifera. J Comp Neurol 499:933-952.

Kleineidam CJ, Obermayer M, Halbich W, Rössler W. 2005. A macroglomerulus in the antennal lobe of leaf-cutting ant workers and its possible functional significance. Chem Senses 30:383-392.

Kleineidam CJ, Rössler W, Hölldobler B, Roces F. 2007. Perceptual differences in trail-following leaf-cutting ants relate to body size. J Insect Physiol 53:1233-1241.

Kuhn-Buhlmann S, Wehner R. 2006. Age-dependent and taskrelated volume changes in the mushroom bodies of visually guided desert ants, Cataglyphis bicolor. J Neurobiol 66:511-521.

Lofgren CS, Vander Meer RK. 1986. Fire ants and leaf-cutting ants: biology and management. Boulder, CO: Westview Press. $435 \mathrm{p}$.

Morgan ED. 2009. Trail pheromones of ants. Physiol Entomol $34: 1-17$.

Morgan ED, Keegans SJ, Tits J, Wenseleers T, Billen J. 2006. Preferences and differences in the trail pheromone of the leafcutting ant Atta sexdens sexdens (Hymenoptera: Formicidae). Eur J Entomol 103:553-558.
Moser JC, Reeve JD, Bento JMS, Della Lucia TMC, Cameron RS, Heck NM. 2004. Eye size and behaviour of day- and nightflying leafcutting ant alates. J Zool 264:69-75.

Mustaparta H. 1990. Chemical information processing in the olfactory system of insects. Part I: periphery. Physiol Rev 70:199-243.

Nijhout HF. 1999. Control mechanisms of polyphenic development in insects-in polyphenic development, environmental factors alter same aspects of development in an orderly and predictable way. Bioscience 49:181-192.

Nijhout HF. 2003. Development and evolution of adaptive polyphenisms. Evol Dev 5:9-18.

Nishikawa M, Nishino H, Misaka Y, Kubota M, Tsuji E, Satoji Y, Ozaki M, Yokohari F. 2008. Sexual dimorphism in the antennal lobe of the ant Camponotus japonicus. Zool Sci 25:195-204.

Sachs L. 1988. Statistische Methoden: Planung und Auswertung. Berlin: Springer. $881 \mathrm{p}$.

Sachse S, Galizia CG. 2002. Role of inhibition for temporal and spatial odor representation in olfactory output neurons: a calcium imaging study. J Neurophysiol 87:1106-1117.

Sandoz JC. 2006. Odour-evoked responses to queen pheromone components and to plant odours using optical imaging in the antennal lobe of the honey bee drone Apis mellifera L. J Exp Biol 209:3587-3598.

Schachtner J, Schmidt M, Homberg U. 2005. Organization and evolutionary trends of primary olfactory brain centers in Tetraconata (Crustacea + Hexapoda). Arthropod Struct Dev 34:257-299.

Spaethe J, Brockmann A, Halbig C, Tautz J. 2007. Size determines antennal sensitivity and behavioral threshold to odors in bumblebee workers. Naturwissenschaften 94:733-739.

Strausfeld NJ, Sinakevitch I, Brown SM, Farris SM. 2009. Ground plan of the insect mushroom body: functional and evolutionary implications. J Comp Neurol 513:265-291.

Strauss R. 2002. The central complex and the genetic dissection of locomotor behaviour. Curr Opin Neurobiol 12:633-638.

Sun XJ, Fonta C, Masson C. 1993. Odor quality processing by bee antennal lobe interneurons. Chem Senses 18:355-377.

Suzuki Y, Nijhout HF. 2008. Genetic basis of adaptive evolution of a polyphenism by genetic accommodation. J Evol Biol 21:57- 66 .

Weber NA. 1972. Gardening ants the attines. Philadelphia: The American Philosophical Society. 146 p.

West-Eberhard MJ. 2005. Developmental plasticity and the origin of species differences. Proc Natl Acad Sci U S A 102:6543- 6549.

Wheeler DE, Nijhout HF. 1983. Soldier determination in Pheidole bicarinata-effect of methoprene on caste and size within castes. J Insect Physiol 29:847-854.

Wheeler DE, Nijhout HF. 1984. Soldier determination in Pheidole bicarinata-inhibition by adult soldiers. J Insect Physiol 30:127-135.

Whitfield CW, Ben-Shahar Y, Brillet C, Leoncini I, Crauser D, LeConte Y, Rodriguez-Zas S, Robinson GE. 2006. Genomic dissection of behavioral maturation in the honeybee. Proc Natl Acad Sci U S A 103:16068-16075.

Wilson EO. 1971. The insect societies. Cambridge, MA: Harvard University Press. 548 p.

Wilson EO. 1980a. Caste and division of labor in leaf-cutter ants (Hymenoptera: Formicidae: Atta). I. The overall pattern in Atta sexdens. Behav Ecol Sociobiol 7:143-156.

Wilson EO. 1980b. Caste and division of labor in leaf-cutter ants (Hymenoptera: Formicidae: Atta). II. The ergonomic optimization of leaf cutting Atta sexdens. Behav Ecol Sociobiol 7:157-165.

Zube C, Rössler W. 2008. Caste- and sex-specific adaptations within the olfactory pathway in the brain of the ant Camponotus floridanus. Arthropod Struct Dev 37:469 - 479.

Zube C, Kleineidam CJ, Kirschner S, Neef J, Rössler W. 2008. Organization of the olfactory pathway and odor processing in the antennal lobe of the ant Camponotus floridanus. J Comp Neurol 506:425-441. 